\title{
Association Between Workarounds and Medication Administration Errors in Bar Code-Assisted Medication Administration: Protocol of a Multicenter Study
}

Willem van der Veen ${ }^{1}$, PharmD; Patricia MLA van den Bemt ${ }^{2}$, PharmD, PhD; Maarten Bijlsma ${ }^{1}$, PhD Statistics; Han J de Gier $^{1}$, PharmD, PhD; Katja Taxis ${ }^{1}$, PharmD, PhD

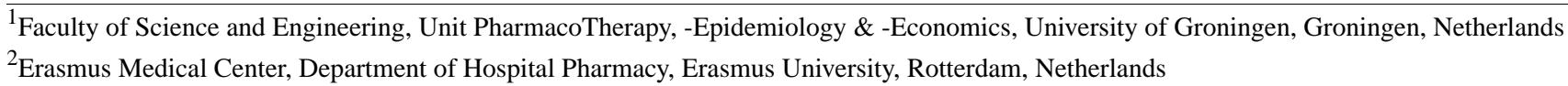

\section{Corresponding Author:}

Willem van der Veen, PharmD

Faculty of Science and Engineering

Unit PharmacoTherapy, -Epidemiology \& -Economics

University of Groningen

HPC: XB45

A Deusinglaan 1

Groningen, 9713 AV

Netherlands

Phone: 31503637576

Fax: 31523615550

Email: willem.van.der.veen@rug.nl

\section{Abstract}

Background: Information technology-based methods such as bar code-assisted medication administration (BCMA) systems have the potential to reduce medication administration errors (MAEs) in hospitalized patients. In practice, however, systems are often not used as intended, leading to workarounds. Workarounds may result in MAEs that may harm patients.

Objective: The primary aim is to study the association of workarounds with MAEs in the BCMA process. Second, we will determine the frequency and type of workarounds and MAEs and explore the potential risk factors (determinants) for workarounds.

Methods: This is a multicenter prospective study on internal medicine and surgical wards of 4 Dutch hospitals using BCMA systems to administer medication. We will include a total of 6000 individual drug administrations using direct observation to collect data.

Results: The project was funded in 2014 and enrollment was completed at the end of 2016. Data analysis is under way and the first results are expected to be submitted for publication at the end of 2017.

Conclusions: If an association between workarounds and MAEs is established, this information can be used to reduce the frequency of MAEs. Information on determinants of workarounds can aid in a focused approach to reduce workarounds and thus increase patient safety.

Trial Registration: Netherlands Trial Register NTR4355; http://www.trialregister.nl/trialreg/admin/rctview.asp?TC=4355 (Archived by WebCite at http://www.webcitation.org/6pqTLxc6i).

(JMIR Res Protoc 2017;6(4):e74) doi: 10.2196/resprot.7060

\section{KEYWORDS}

BCMA; bar code-assisted medication administration systems; workarounds; medication administration errors; bar coded medication administration; medication safety, hospitals

\section{Introduction}

Minimizing the risks of prescribing and medication administration is important to enhance patient safety in hospitals
[1-6]. Many hospitals have implemented information technology-based systems such as computerized physician order entry (CPOE) systems to reduce prescribing errors [7-10]. Some have also implemented electronic bar code-assisted medication 
administration (BCMA) systems to reduce medication administration errors (MAEs) [11-18]. BCMA systems are designed to contribute to patient safety through scanning of the bar code on the medication package and the bar code on the patient's identification wristband to guarantee the 5 "rights" in patient medication administration: right patient, right medication, right dose, right route, and the right time. However, in practice, BCMA systems are not always used as intended, and so-called workaround occurs [19-23]. Kobayashi et al [24] defined workarounds as "informal temporary practices for handling exceptions to normal workflow." Investigating the use of CPOE systems in hospitals, Niazkhani et al [25] described 42 types of workarounds. Koppel et al [26] documented 15 types of workarounds in the BCMA process, including affixing patients' identification bar codes to computer carts and carrying several patients' prescanned medications on carts. That study documented 31 roots of these workarounds. Research on workarounds in the BCMA process focused on the qualitative description of the extent and type of workarounds in the BCMA process $[27,28]$. Little research has been done to quantify the frequency of workarounds in the BCMA process and investigate the impact of workarounds on patient safety, in particular, MAEs as a potential consequence of workarounds. Furthermore, little is known about the potential risk factors leading to workarounds. Therefore, we designed a study aimed at determining the association of workarounds with MAEs. Our secondary objectives are to determine the frequency and type of workarounds and the frequency and type of MAE, and to identify potential risk factors for workarounds.

\section{Methods}

\section{Design}

This study is a multicenter prospective observational study in adult patients who are admitted to a participating hospital in the Netherlands and who have their medication administered by BCMA systems.

The regional medical ethics committee (Regionale Medisch Ethische Commissie Zorgpartners Friesland) approved the study protocol. Study data are coded to guarantee the privacy of the participants.

\section{Setting}

All included hospitals have implemented CPOE [10] and BCMA systems. They use a variety of software packages, both for the CPOE and for the BCMA systems. As a consequence, procedures for prescribing and medication administration differ between hospitals. Table 1 summarizes the main characteristics. Medication administration procedures within a hospital vary slightly between wards because of differences in patient groups or tasks (eg, in some hospitals, short stay surgical patients do not wear wristbands, but these are attached to the medication cart).

The included hospitals use bar code-labeled unit dose systems to distribute medication to inpatients. In the pharmacy departments, pharmacy technicians dispense bar coded medication for individual patients into trays labeled with the patient's name and bar code. Trays are placed in medication carts in which they are then delivered to the wards once a day (or more frequently). Wards do not have ward-based medication stock (except for emergency medication). One of the selected hospitals uses so-called bedside assortment picking carts [29]. A cart contains all the medication commonly used on the ward. With this system, nurses select the medication for administration during the medication administration rounds.

In general, there are 4 scheduled medication administration rounds in the participating hospitals: 6-10 AM, 10-2 PM, 6-8 PM, and 8-10 PM. Medications are administered by 1 nurse. Nurse trainees are supervised by registered nurses. In the participating hospitals, there are approximately 10-20 inpatients admitted on a ward served by a registered nurse and a nurse trainee. A large ward is split into smaller units each serving 10-20 inpatients, each aided by a registered nurse and a nurse trainee.

During a drug administration round, nurses select the prescribed medication for each inpatient from the prefilled trays or from the bedside assortment picking carts. In addition to the cart, nurses also take along the computer on wheels or the workstation on wheels to access the CPOE system during the drug administration round.

Inpatients do not use their own (out-of-hospital prescribed) drugs.

\section{Participants}

The study will enroll patients admitted to the internal medicine and surgical wards of 4 Dutch hospitals in which a BCMA system is used to administer medication. To be eligible to participate in this study, a participant must meet the following criteria: be a hospitalized patient and receive medication on those nursing wards that are participating in this study. We will exclude patients younger than 18 years.

\section{Outcome Measures}

The primary outcome measure of the study is the proportion of medication administrations with 1 or more MAEs. For this outcome, we will study the association between the MAE and the occurrence of 1 or more workarounds.

The secondary outcomes are the frequency and type of workarounds, the frequency and type of MAEs in the BCMA process, and the association of potential risk factors with workarounds. 
Table 1. Characteristics of the medication administration systems in the participating hospitals.

\begin{tabular}{|c|c|c|c|c|}
\hline Item & Hospital 1 & Hospital 2 & Hospital 3 & Hospital 4 \\
\hline Software system & RH Dharma & ViPharma & Klinicom & Pharma \\
\hline System screen layout & Fixed layout & Fixed layout & Fixed layout & $\begin{array}{l}\text { User-controlled screen lay- } \\
\text { out }\end{array}$ \\
\hline Administration system & $\begin{array}{l}\text { Bedside assortment picking } \\
\text { cart }\end{array}$ & $\begin{array}{l}\text { Cart with prefilled patient- } \\
\text { labeled trays }\end{array}$ & $\begin{array}{l}\text { Cart with prefilled patient- } \\
\text { labeled trays }\end{array}$ & $\begin{array}{l}\text { Cart with prefilled patient- } \\
\text { labeled trays }\end{array}$ \\
\hline Log-in procedure for nurse & $\begin{array}{l}\text { Once; automatic log-out af- } \\
\text { ter } 15 \text { minutes of inactivity }\end{array}$ & Once for 1 session & Once for 1 session & Once for 1 session \\
\hline Log-out procedure for nurse & $\begin{array}{l}\text { Manual; automatic log-out } \\
\text { after } 15 \text { minutes of inactivity }\end{array}$ & Manual & Manual & Manual \\
\hline $\begin{array}{l}\text { Built-in additional check by } \\
\text { nurse's colleagues }\end{array}$ & $\begin{array}{l}\text { Extra log-in for another } \\
\text { nurse built in }\end{array}$ & Not possible & $\begin{array}{l}\text { Extra log-in for another } \\
\text { nurse built in }\end{array}$ & $\begin{array}{l}\text { Not described in the instruc- } \\
\text { tions }\end{array}$ \\
\hline Signal/alert system & $\begin{array}{l}\text { Scanner beep and scanner } \\
\text { warning light }\end{array}$ & Computer beep & Computer beep & Computer beep \\
\hline Patient has no bar code & $\begin{array}{l}\text { Not described in the instruc- } \\
\text { tions }\end{array}$ & Manual patient selection & Manual patient selection & Manual patient selection \\
\hline $\begin{array}{l}\text { Patient selection per admin- } \\
\text { istration round }\end{array}$ & $\begin{array}{l}\text { Once, by selection of pa- } \\
\text { tient; automatically deselect- } \\
\text { ed after all medication for } \\
\text { that round is administered }\end{array}$ & $\begin{array}{l}\text { Twice, by selection and ac- } \\
\text { tive deselection of patient } \\
\text { after medication administra- } \\
\text { tion }\end{array}$ & $\begin{array}{l}\text { Once, by selection of pa- } \\
\text { tient; automatic deselection } \\
\text { after all medication for that } \\
\text { round is administered }\end{array}$ & $\begin{array}{l}\text { Once, by selection of pa- } \\
\text { tient; automatic deselection } \\
\text { after all medication for that } \\
\text { round is administered }\end{array}$ \\
\hline $\begin{array}{l}\text { Medication in the cart has } \\
\text { no bar code }\end{array}$ & $\begin{array}{l}\text { Robot-packed bar coded } \\
\text { medication ordered from } \\
\text { pharmacy }\end{array}$ & Manual drug selection & Manual drug selection & $\begin{array}{l}\text { Nurse can overrule the sys- } \\
\text { tem using her or his access } \\
\text { code and manually select } \\
\text { drug }\end{array}$ \\
\hline $\begin{array}{l}\text { More than } 1 \text { unit of the same } \\
\text { drug for the same time pre- } \\
\text { scribed }\end{array}$ & $\begin{array}{l}\text { Scanned once, then the } \\
\text { number of tablets is manual- } \\
\text { ly adjusted }\end{array}$ & Every drug unit is scanned & $\begin{array}{l}\text { Scanned once, then the } \\
\text { number of tablets is manual- } \\
\text { ly adjusted }\end{array}$ & $\begin{array}{l}\text { Scanned once; a pop-up ap- } \\
\text { pears asking for the other } \\
\text { tablets to be scanned }\end{array}$ \\
\hline Patient away or sleeping & $\begin{array}{l}\text { Prescribed medication is } \\
\text { placed at the patients' bed- } \\
\text { side, registered as given, and } \\
\text { checked at 2:00 AM }\end{array}$ & $\begin{array}{l}\text { Medication not given and } \\
\text { not registered; noted in } \\
\text { memo field }\end{array}$ & $\begin{array}{l}\text { Medication not given and } \\
\text { not registered; noted in } \\
\text { memo field }\end{array}$ & $\begin{array}{l}\text { Not described in the instruc- } \\
\text { tions }\end{array}$ \\
\hline $\begin{array}{l}\text { One-half or one-quarter of a } \\
\text { tablet prescribed }\end{array}$ & $\begin{array}{l}\text { Tablet scanned, plus code } \\
\text { "half" or "quarter" scanned } \\
\text { on computer }\end{array}$ & $\begin{array}{l}\text { Not described in the instruc- } \\
\text { tions }\end{array}$ & $\begin{array}{l}\text { Tablet scanned, plus noted } \\
\text { by nurse in memo field on } \\
\text { the screen }\end{array}$ & $\begin{array}{l}\text { Not described in the instruc- } \\
\text { tions }\end{array}$ \\
\hline $\begin{array}{l}\text { Instructions on screen for } \\
\text { nurse from pharmacy or } \\
\text { prescriber }\end{array}$ & $\begin{array}{l}\text { On-screen memo field in- } \\
\text { cluded (medication data } \\
\text { level) }\end{array}$ & $\begin{array}{l}\text { On-screen memo field in- } \\
\text { cluded (patient data level) }\end{array}$ & $\begin{array}{l}\text { On-screen memo field in- } \\
\text { cluded (medication data } \\
\text { level) }\end{array}$ & $\begin{array}{l}\text { On-screen memo field in- } \\
\text { cluded (medication data } \\
\text { level) }\end{array}$ \\
\hline
\end{tabular}

We will collect the following potential risk factors for workarounds using a structured data collection form (Multimedia Appendix 1): nurses' characteristics (experienced, trained, or student nurse; nurses' satisfaction with BCMA), workload characteristics (number of nurses on the ward, number of patients served by that ward, number of medicines per round per patient, number of medicines for all patients per round per ward), BCMA system characteristics (time after implementation of BCMA system on that ward, bar code on medication unit dose), medication characteristics (Anatomical Therapeutic Chemical Classification System [ATC] code of the medication, drug administration route), and general characteristics (hospital type, ward type, time of ward round, patient age and sex). We will ask the supervisor of the ward for data on the nurses' education and experience. We will extract the number of patients on the ward, the medication and ATC code, and the number of drugs to administer to each individual patient during the specific

administration rounds from the CPOE system. We will ask the supervising hospital pharmacist for the other risk factors.

\section{Data Collection}

We will use disguised observation [30-34] to collect data. A total of 3 trained observers (undergraduate students, writing their master's thesis) from the School of Pharmacy, University of Groningen and Utrecht University, the Netherlands, will observe the nurses while they give drugs to inpatients. To prevent nurses adjusting their behavior in the BCMA process while under observation, the observer will be introduced as being on the ward to monitor the performance of the medication distribution system on that ward. The observer will take part in several planned medication administration rounds on that ward and also observe unscheduled medication administrations. The observer will randomly pick a medication administration round with a minimum of 3 rounds every day and a weekly minimum of 18 rounds. During the different rounds, the observer will observe as many different nurses as possible. To prepare for the 
observation, the observer will study the standard operating procedures or the applicable drug administration procedures of the specific ward and the agreements on the BCMA process of that ward. In practice, the observer will accompany the nurse who administers the medication using the BCMA system and observe the administration of each dose of medication to the patient. The observer will record the nurses' actions of giving drugs to the patients (according to the forms in Multimedia Appendix 1,Multimedia Appendix 2, and Multimedia Appendix 3). After each observed medication administration round, we will collect a (printed) computer output of the medication for that specific patient, day, and round from the hospital's electronic patient records. Consequently, we will compare observation records with the prescribed medication on this computer output and with available standard operating procedures of the BCMA process for that specific ward, to identify workarounds and MAEs. We designed an Access database in which we will record the observation data and which we will link to each patient's prescription and medication data.

If the observer becomes aware of a potentially serious error, the observer will intervene for ethical reasons, but the data will be included in the study.

\section{Training of the Observers}

We will train our observers by having them study relevant literature on observational techniques [19,30,34-40], perform practical observations in a nonparticipating hospital under the supervision of the research team, and complete a written theoretical exam. The observers will have to pass the exam scoring 8 out of 10 points, having two chances to pass the exam. In case of a second failure, he or she will not be able to observe. Each observer will do pilot observations in a participating hospital, supervised by 1 of the researchers, for 1 week on the wards, to become familiar with the BCMA process. Pilot observations will be discussed with the research team. These observations are meant as a final training of the observer. Pilot data will be discarded.

\section{Definitions and Classification}

Workarounds are defined as "informal temporary practices for handling exceptions to normal workflow" for that specific ward and are operationalized as deviations from the available protocols [24]. Figure 1 depicts the BCMA workflow and the potential risk factors for workarounds in the BCMA process. We will classify workarounds using a self-developed classification system (Table 2) derived from the system of Koppel et al [26]. Workarounds can be related to patient identification, the scanning process, the alert signals, and other procedures, or can be work related. Allan and Barker [41] defined MAEs as "the administration of a dose of medication that deviates from the prescription as written (or ordered by CPOE) on the patient medication chart, or from standard hospital policy and procedures." We will compare drug administrations with the doctor's prescriptions as noted in the CPOE system in the pharmacy database. We will exclude intravenous and nonintravenous preparation errors because these errors are not preventable by BCMA and are thus unlikely to be influenced by workarounds in the BCMA process. We will classify the MAEs using the classification of van den Bemt et al [42] (Table 3 ). We will divide the number of erroneous medication administrations (containing 1 or more errors) by the number of observed drug administrations plus the number of omissions, thus using the concept of opportunities for errors as in other MAE research [43]. 
Figure 1. Flowchart of the bar code-assisted medication administration (BCMA) process in hospitals.

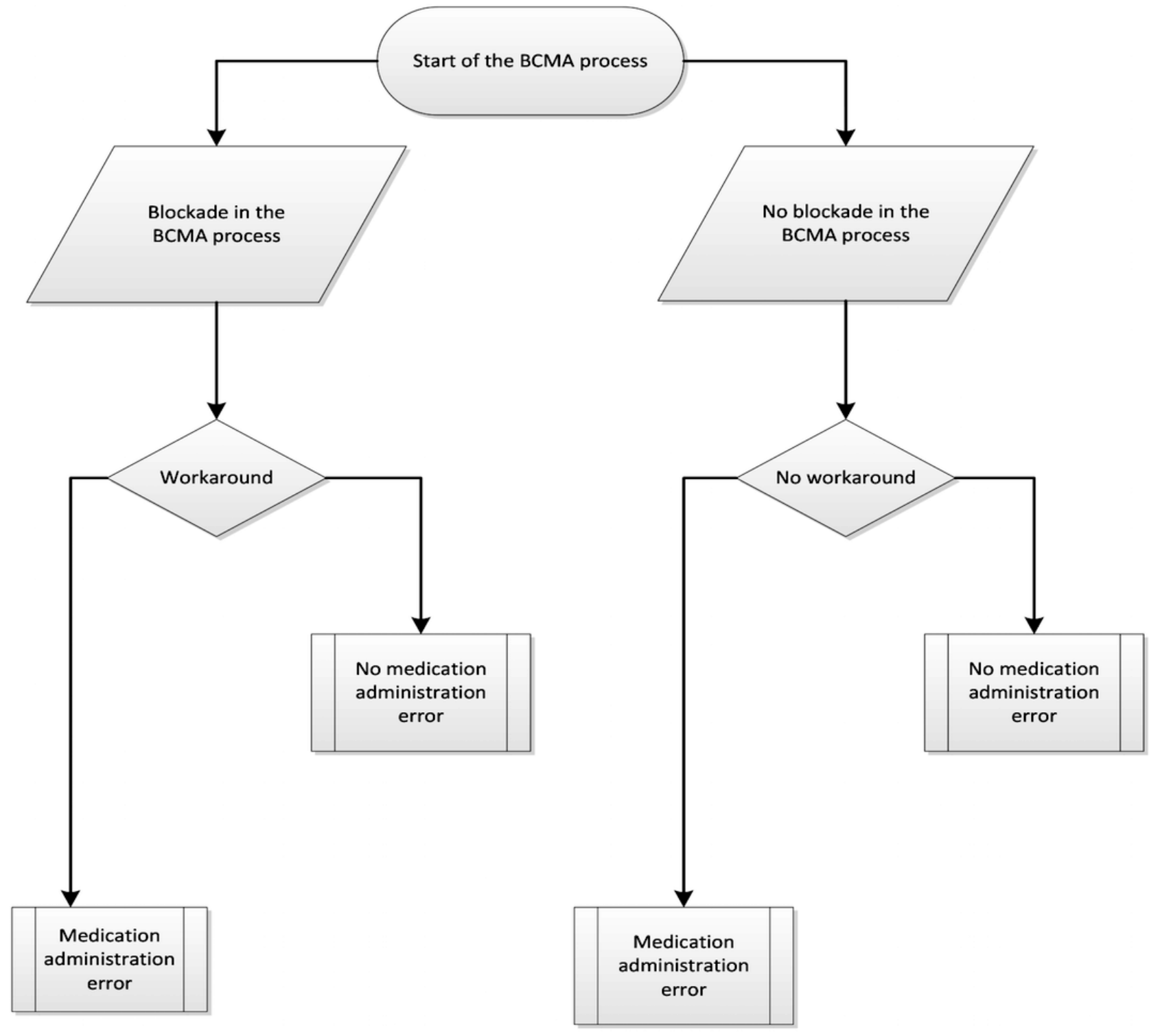

Table 2. Classification of workarounds in the bar code-assisted medication administration process ${ }^{\mathrm{a}}$.

\begin{tabular}{ll}
\hline Workaround type & Example workaround \\
\hline Procedure related: standard operating procedure, or procedure unclear or unknown & Nothing scanned \\
Patient related: no patient wristband or patient not in the room & Bed scanned, or loose wristband scanned, patient unscanned \\
Medication related: medication not bar coded & Unscanned, unidentified medication given \\
Nurse related: nurse disturbed & Nurse forgets patient or gives medication twice \\
Computer or scanner related: computer or scanner down or broken & Signals or alerts unseen, unscanned medication given \\
Other workarounds & $\begin{array}{l}\text { Medication scanned for multiple patients; half tablets scanned } \\
\text { as full dose }\end{array}$ \\
\hline
\end{tabular}

${ }^{\mathrm{a}}$ Derived from Koppel et al [26]. 
Table 3. The most basic characterization of medication administration errors (MAEs) ${ }^{\mathrm{a}}$.

\begin{tabular}{|c|c|}
\hline MAE type & Example MAE \\
\hline Omission & Drug prescribed, but not administered \\
\hline Unordered drug administration & Drug administered, but not prescribed \\
\hline Wrong dosage form & $\begin{array}{l}\text { Drug dosage form administered to the patient deviating from prescribed dosage form: solution as an alternative } \\
\text { to tablet }\end{array}$ \\
\hline Wrong route of administration & Drug given by a wrong route of administration: oral liquid administered intravenously \\
\hline Wrong administration technique & Drug administered using a wrong technique: intravenous push instead of intravenous infusion \\
\hline Wrong dosage & Drug dosage too high or low: $20 \mathrm{mg}$ instead of $20 \mu \mathrm{g}$ \\
\hline Wrong time of administration & Drug given at least 60 minutes too early or too late \\
\hline
\end{tabular}

${ }^{\mathrm{a}}$ From van den Bemt et al [42].

\section{Sample Size Calculation}

Prior studies [14,44-46] on the effect of BCMA show a substantial reduction (about 30\%) of errors after the implementation of BCMA (from 14.4\%, or 4743 errors in 32,972 observations, to $9.9 \%$, or 2651 errors in 26,892 observations). The error rate of about $10 \%$ is a mix of all resulting errors, including those caused by workarounds. The purpose of our sample size calculation is to estimate the number of observations needed to reject the null hypothesis with a power of $90 \%$. We performed a pilot study in 4 Dutch hospitals that were partially using BCMA (these hospitals did not participate in our final research) and found MAE rates, including time window errors caused by nurses and based on workarounds, fluctuating from $2 \%$ to $20 \%(2 \%, 4 \%, 5 \%$, and $20 \%)$. We assume in our sample size calculation that $8 \%$ of medication administrations per patient per nurse result in a workaround. We also assume that the MAE rate associated with a workaround is 2-fold compared with the situation without a workaround; that gives us a relative risk of 2. With alpha of .05 and a power of 0.9 , we need to observe 1500 individual medication administrations to patients per hospital to reject the null hypothesis.

\section{Data Monitoring}

We will enter all data into an Access database (version 2010, Microsoft Corporation). The basis for the Access database will be the case report forms in Multimedia Appendix 1,Multimedia Appendix 2, and Multimedia Appendix 3. The first (Multimedia Appendix 1) is designed to collect data on potential risk factors for workarounds, the second (Multimedia Appendix 2) is designed to collect data on MAEs, and the third (Multimedia Appendix 3) is designed to collect data on observations of workarounds. These data will be made available to other researchers and editors on request. Data entry errors will be minimized by using multiple choice options and fixed data fields. At the end of the study, $10 \%$ of the entered data will be checked by a second researcher. If data entry errors are found, additional portions of $10 \%$ of the data will be checked until no errors are found within a portion. Also, a periodic backup of the study database of each hospital will be made and checked for missing data. Access to the research databases will be secured by passwords. Changing the format of the study documentation or study databases will be restricted to the primary investigator. New versions will be distributed from the central study location (the University of Groningen, the Netherlands). Before data analysis, we will lock the final database.

\section{Statistical Analysis}

Data will be analyzed using IBM SPSS Statistics version 22 (IBM Corporation). We will analyze the potential association between workarounds and the occurrence of MAEs using univariate multilevel logistic regression, with the proportion of medication administrations with 1 or more errors as the dependent variable and the occurrence of workarounds as the independent variable. The nurse and the patient will be the levels in the multilevel analysis. We will analyze the occurrence of workarounds as a categorical variable, with the following categories: no workarounds (reference category), 1 workaround, 2 workarounds, and 3 or more workarounds. We will adjust for potential confounders by using multivariate multilevel logistic regression. The parameters in the multivariate multilevel logistic regression model will be hospital, ward type, day of the week, time schedule of medication administration rounds, ATC code, the number of drugs per patient per round, and the route of administration. We will report the adjusted odds ratio and 95\% confidence interval. For the frequency and type of workarounds and MAEs, we will use descriptive statistics. Univariate and multivariate logistic regression will determine the association of the risk factors with the workarounds.

\section{Results}

The project was funded in 2014 and enrollment was completed at the end of 2016. Data analysis is under way and the first results are expected to be submitted for publication at the end of 2017.

\section{Discussion}

The Dutch BCMA study investigates the complex and multifaceted process of medication administration to hospital inpatients. Computer technology can assist not only the prescribing and dispensing of drugs, but also their administration. Several studies have shown that BCMA systems can contribute to patient safety in this final step of the medication distribution process [11-18]. On the other hand, computer technology can give rise to new MAEs, as is described 
in the literature [47]. Many of these errors occur at the human-machine interface, for example, due to inadequate training or understanding of the system or inadequate equipment. Such factors may lead to workarounds that may compromise patient safety. Although several articles have been published describing workarounds in a qualitative way, very little is known on whether they are associated with a higher risk of MAEs.

\section{Strengths and Limitations}

The strength of the Dutch BCMA study is that it will provide quantitative information about workarounds and their possible association with MAEs, as one of the first studies worldwide, to our knowledge. Other strengths are the multicenter design, which enhances its generalizability, and the robust method of data collection by disguised observation.

There are some limitations and considerations, however. An important limitation, in general, is that the use of BCMA cannot prevent all MAEs. For example, BCMA systems will have no influence on the preparation of intravenous and nonintravenous medication. So, although this study will contribute to patient safety, further studies into other ways of preventing MAEs will remain necessary.

Although disguised observation is the best method for data collection in MAE studies, some limitations are associated with this technique. Despite thorough training of the observers, bias may still occur. To overcome observation bias, we considered the use of the work observation method by activity timing $[34,48]$. This elegant paperless method is used for time- and activity-based observations and is less suitable for observing workarounds and MAEs.

The observations may influence the nurse but, from the literature, we know that this effect (known as Hawthorne effect) $[49,50]$ is small. The observer may also become tired and thus less accurate. How to train observers is not well documented in the literature. Patterson et al [19] performed an observational study in acute and long-term care wards using observers trained in ethnographic observations in complex settings. Other researchers trained nurse students as observers [51]. We will use all possible means, as well as the best possible literature base, to train the students.

We will try to reduce confounding by applying multivariate regression analyses (eg, hospital type, type of ward). However, in this type of observational study design, residual confounding may always remain [52].

Last but not least, we plan to conduct our research on internal medicine and surgical hospital wards. Although these nursing wards cover a broad range of patient categories, our findings cannot be generalized to all patient categories.

\section{Conclusion}

BCMA has the potential to minimize the occurrence of MAEs, but workarounds may compromise this. Knowing how nurses overcome process barriers by using workarounds and their association with MAEs will produce opportunities to further increase patient safety in the process of BCMA.

\section{Authors' Contributions}

$\mathrm{WV}, \mathrm{PB}$, and KT designed the study and drafted the manuscript. MB and HG made substantial contributions to the design of the protocol. All authors read and approved the final manuscript.

This research received no specific grant from any funding agency in public, commercial, or not-for-profit sectors.

\section{Conflicts of Interest}

None declared.

\section{Multimedia Appendix 1}

Potential risk factors form.

[PDF File (Adobe PDF File), 15KB-Multimedia Appendix 1]

\section{Multimedia Appendix 2}

Medication administration errors observation form.

[PDF File (Adobe PDF File), 16KB-Multimedia Appendix 2]

\section{Multimedia Appendix 3}

Workarounds observation form.

\section{[PDF File (Adobe PDF File), 15KB-Multimedia Appendix 3]}

\section{References}

1. Breckenridge RA. Technology and patient safety: only part of the solution. Br J Hosp Med (Lond) 2010 Oct;71(10):544-545. [doi: 10.12968/hmed.2010.71.10.78934] [Medline: 21085067]

2. Hagland M. CPOE and patient safety. Healthe Inform 2011 Jun;28(6):76-78. [Medline: 21736218] 
3. Handel DA, Wears RL, Nathanson LA, Pines JM. Using information technology to improve the quality and safety of emergency care. Acad Emerg Med 2011 Jun;18(6):e45-e51 [FREE Full text] [doi: 10.1111/j.1553-2712.2011.01070.x] [Medline: 21676049]

4. Holden RJ. What stands in the way of technology-mediated patient safety improvements?: a study of facilitators and barriers to physicians' use of electronic health records. J Patient Saf 2011 Dec;7(4):193-203 [FREE Full text] [doi: 10.1097/PTS.0b013e3182388cfa] [Medline: 22064624]

5. Wulff K, Cummings GG, Marck P, Yurtseven O. Medication administration technologies and patient safety: a mixed-method systematic review. J Adv Nurs 2011 Oct;67(10):2080-2095. [doi: 10.1111/j.1365-2648.2011.05676.x] [Medline: 21545642]

6. Institute of Medicine. Health IT and Patient Safety: Building Safer Systems For Better Care. Washington, DC: The National Academies Press; 2012.

7. Aarts J, Koppel R. Implementation of computerized physician order entry in seven countries. Health Aff (Millwood) 2009;28(2):404-414 [FREE Full text] [doi: 10.1377/hlthaff.28.2.404] [Medline: 19275996]

8. van Doormaal JE, Mol PG, Zaal RJ, van den Bemt PM, Kosterink JG, Vermeulen KM, et al. Computerized physician order entry (CPOE) system: expectations and experiences of users. J Eval Clin Pract 2010 Aug;16(4):738-743. [doi: 10.1111/j.1365-2753.2009.01187.x] [Medline: 20545801]

9. Hollister D, Messenger A. Implementation of computerized physician order entry at a community hospital. Conn Med 2011 Apr;75(4):227-233. [Medline: 21560729]

10. van der Veen W, de Gier HJ, van der Schaaf T, Taxis K, van den Bemt PM. Risk analysis and user satisfaction after implementation of computerized physician order entry in Dutch hospitals. Int J Clin Pharm 2013 Apr;35(2):195-201. [doi: 10.1007/s11096-012-9727-y] [Medline: 23187963]

11. Agrawal A, Glasser AR. Barcode medication. Administration implementation in an acute care hospital and lessons learned. J Healthc Inf Manag 2009;23(4):24-29. [Medline: 19894483]

12. Marini SD, Hasman A. Impact of BCMA on medication errors and patient safety: a summary. Stud Health Technol Inform 2009;146:439-444. [Medline: 19592882]

13. Helmons PJ, Wargel LN, Daniels CE. Effect of bar-code-assisted medication administration on medication administration errors and accuracy in multiple patient care areas. Am J Health Syst Pharm 2009 Jul 1;66(13):1202-1210. [doi: 10.2146/ajhp080357] [Medline: 19535659]

14. DeYoung JL, Vanderkooi ME, Barletta JF. Effect of bar-code-assisted medication administration on medication error rates in an adult medical intensive care unit. Am J Health Syst Pharm 2009 Jun 15;66(12):1110-1115. [doi: 10.2146/ajhp080355] [Medline: 19498127]

15. Young J, Slebodnik M, Sands L. Bar code technology and medication administration error. J Patient Saf 2010 Jun;6(2):115-120. [doi: 10.1097/PTS.0b013e3181de35f7] [Medline: 22130354]

16. Miller DF, Fortier CR, Garrison KL. Bar code medication administration technology: characterization of high-alert medication triggers and clinician workarounds. Ann Pharmacother 2011 Feb;45(2):162-168. [doi: 10.1345/aph.1P262] [Medline:

21285409]

17. Holden RJ, Brown RL, Alper SJ, Scanlon MC, Patel NR, Karsh B. That's nice, but what does IT do? Evaluating the impact of bar coded medication administration by measuring changes in the process of care. Int J Ind Ergon 2011 Jul 01;41(4):370-379 [FREE Full text] [doi: 10.1016/j.ergon.2011.02.007] [Medline: 21686318]

18. Berdot S, Gillaizeau F, Caruba T, Prognon P, Durieux P, Sabatier B. Drug administration errors in hospital inpatients: a systematic review. PLoS One 2013;8(6):e68856 [FREE Full text] [doi: 10.1371/journal.pone.0068856] [Medline: 23818992]

19. Patterson ES, Rogers ML, Chapman RJ, Render ML. Compliance with intended use of bar code medication administration in acute and long-term care: an observational study. Hum Factors 2006;48(1):15-22. [doi: 10.1518/001872006776412234] [Medline: 16696253]

20. Van Der Sijs H, Rootjes I, Aarts J. The shift in workarounds upon implementation of computerized physician order entry. Stud Health Technol Inform 2011;169:290-294. [Medline: 21893759]

21. Rathert C, Williams ES, Lawrence ER, Halbesleben JR. Emotional exhaustion and workarounds in acute care: cross sectional tests of a theoretical framework. Int J Nurs Stud 2012 Aug;49(8):969-977. [doi: 10.1016/j.ijnurstu.2012.02.011] [Medline: 22391337]

22. Seidling HM, Lampert A, Lohmann K, Schiele JT, Send AJ, Witticke D, et al. Safeguarding the process of drug administration with an emphasis on electronic support tools. Br J Clin Pharmacol 2013 Sep;76 Suppl 1:25-36 [FREE Full text] [doi: 10.1111/bcp.12191] [Medline: 24007450]

23. Voshall B, Piscotty R, Lawrence J, Targosz M. Barcode medication administration work-arounds: a systematic review and implications for nurse executives. J Nurs Adm 2013 Oct;43(10):530-535. [doi: 10.1097/NNA.0b013e3182a3e8ad] [Medline: 24061586]

24. Kobayashi M, Fussell S, Xiao Y, Seagull F. Work coordination, workflow, and workarounds in a medical context. New York, NY: ACM Press; 2005 Presented at: CHI '05 Extended Abstracts on Human Factors in Computing Systems; Apr 2-7, 2005; Portland, OR, USA p. 1561-1564. [doi: 10.1145/1056808.1056966] 
25. Niazkhani Z, Pirnejad H, van der Sijs H, Aarts J. Evaluating the medication process in the context of CPOE use: the significance of working around the system. Int J Med Inform 2011 Jul;80(7):490-506. [doi: 10.1016/j.ijmedinf.2011.03.009] [Medline: 21555237]

26. Koppel R, Wetterneck T, Telles JL, Karsh B. Workarounds to barcode medication administration systems: their occurrences, causes, and threats to patient safety. J Am Med Inform Assoc 2008;15(4):408-423 [FREE Full text] [doi: 10.1197/jamia.M2616] [Medline: 18436903 ]

27. Rack LL, Dudjak LA, Wolf GA. Study of nurse workarounds in a hospital using bar code medication administration system. J Nurs Care Qual 2012;27(3):232-239. [doi: 10.1097/NCQ.0b013e318240a854] [Medline: 22202186]

28. Henneman PL, Marquard JL, Fisher DL, Bleil J, Walsh B, Henneman JP, et al. Bar-code verification: reducing but not eliminating medication errors. J Nurs Adm 2012 Dec;42(12):562-566. [doi: 10.1097/NNA.0b013e318274b545] [Medline: 23151928]

29. Ros H, De Vreeze-Wesselink E. Reducing the number of dispensing errors by implementing a combination of a CPOE system and a bar-code-assisted dispensing system: the BAP concept. Eur J Hosp Pharm Sci 2009;15(4):86-92.

30. Barker KN, Flynn EA, Pepper GA. Observation method of detecting medication errors. Am J Health Syst Pharm 2002 Dec 01;59(23):2314-2316. [Medline: 12489369]

31. Berdot S, Sabatier B, Gillaizeau F, Caruba T, Prognon P, Durieux P. Evaluation of drug administration errors in a teaching hospital. BMC Health Serv Res 2012 Mar 12;12:60 [FREE Full text] [doi: 10.1186/1472-6963-12-60] [Medline: 22409837]

32. Wirtz V, Taxis K, Barber ND. An observational study of intravenous medication errors in the United Kingdom and in Germany. Pharm World Sci 2003 Jun;25(3):104-111. [Medline: 12840963]

33. Westbrook JI, Woods A. Development and testing of an observational method for detecting medication administration errors using information technology. Stud Health Technol Inform 2009;146:429-433. [Medline: 19592880]

34. Westbrook JI, Ampt A. Design, application and testing of the Work Observation Method by Activity Timing (WOMBAT) to measure clinicians' patterns of work and communication. Int J Med Inform 2009 Apr;78 Suppl 1:S25-S33. [doi: 10.1016/j.ijmedinf.2008.09.003] [Medline: 18951838]

35. Holmwood C. Direct observation. A primer for supervisors of doctors in training. Aust Fam Physician 1998;27(1-2):48-51. [Medline: 9503706]

36. Moravansky I. [Training in observation as a means of promotion of personality development]. Osterr Krankenpflegez 1996 Apr;49(4):30-31. [Medline: 8788712]

37. Riemer JW. A review with a special note on research ethics and disguised observation. Wisc Sociol 1977;14(2-3):87-97. [Medline: 11650450$]$

38. Unertl KM, Weinger MB, Johnson KB. Applying direct observation to model workflow and assess adoption. AMIA Annu Symp Proc 2006:794-798 [FREE Full text] [Medline: 17238450]

39. van der Sande JP. Gedragsobservatie. Een Inleiding tot Systematisch Observeren. 3rd edition. Groningen, the Netherlands: Martinus Nijhoff; 1999.

40. Cristoph L, van der Sande JP. Gedragsobservatie. Systematisch Observeren. 1st edition. Groningen, the Netherlands: Wolters-Noordhoff; 1999.

41. Allan EL, Barker KN. Fundamentals of medication error research. Am J Hosp Pharm 1990 Mar;47(3):555-571. [Medline: 2180287]

42. van den Bemt P. Drug-related problems: definitions and classifications. Eur J Hosp Pharm Pract 2006;12(suppl):10-12.

43. Keers RN, Williams SD, Cooke J, Ashcroft DM. Prevalence and nature of medication administration errors in health care settings: a systematic review of direct observational evidence. Ann Pharmacother 2013 Feb;47(2):237-256. [doi: 10.1345/aph.1R147] [Medline: 23386063]

44. Poon EG, Keohane CA, Yoon CS, Ditmore M, Bane A, Levtzion-Korach O, et al. Effect of bar-code technology on the safety of medication administration. N Engl J Med 2010 May 6;362(18):1698-1707. [doi: 10.1056/NEJMsa0907115] [Medline: 20445181]

45. McLeod MC, Barber N, Franklin BD. Methodological variations and their effects on reported medication administration error rates. BMJ Qual Saf 2013 Apr;22(4):278-289. [doi: 10.1136/bmjqs-2012-001330] [Medline: 23322752]

46. Hassink JJ, Essenberg MD, Roukema JA, van den Bemt PM. Effect of bar-code-assisted medication administration on medication administration errors. Am J Health Syst Pharm 2013 Apr 01;70(7):572-573. [doi: 10.2146/ajhp120257] [Medline: 23515508]

47. Cheung K, van der Veen W, Bouvy ML, Wensing M, van den Bemt PM, de Smet PA. Classification of medication incidents associated with information technology. J Am Med Inform Assoc 2014 Feb;21(e1):e63-e70 [FREE Full text] [doi: 10.1136/amiajnl-2013-001818] [Medline: 24064444]

48. Westbrook JI, Creswick NJ, Duffield C, Li L, Dunsmuir WT. Changes in nurses' work associated with computerised information systems: opportunities for international comparative studies using the revised Work Observation Method By Activity Timing (WOMBAT). NI 2012;2012:448 [FREE Full text] [Medline: 24199139]

49. Gale EA. The Hawthorne studies-a fable for our times? QJM 2004 Jul;97(7):439-449. [Medline: 15208432]

50. Dean BS, Barber ND. A validated, reliable method of scoring the severity of medication errors. Am J Health Syst Pharm 1999 Jan 01;56(1):57-62. [Medline: 10048880] 
51. Kim J, Bates DW. Medication administration errors by nurses: adherence to guidelines. J Clin Nurs 2013 Feb;22(3-4):590-598. [doi: 10.1111/j.1365-2702.2012.04344.x] [Medline: 23228148]

52. Mann B, Wood E. Confounding in observational studies explained. Open Epidemiol J 2012 May 16;5(1):18-20. [doi: 10.2174/1874297101205010018]
Abbreviations
ATC: Anatomical Therapeutic Chemical Classification System
BCMA: bar code-assisted medication administration
CPOE: computerized physician order entry
MAE: medication administration error

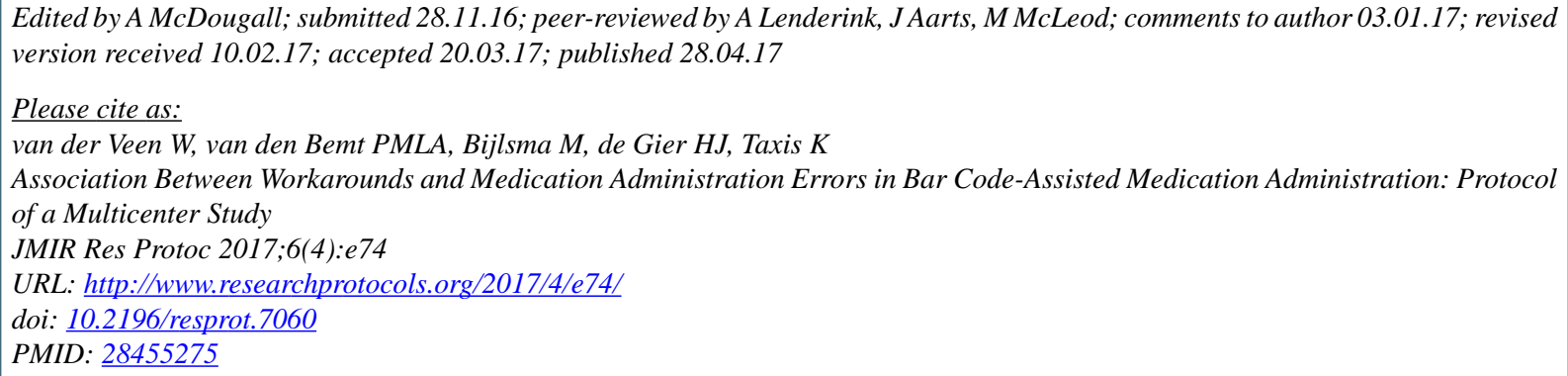

(CWillem van der Veen, Patricia MLA van den Bemt, Maarten Bijlsma, Han J de Gier, Katja Taxis. Originally published in JMIR Research Protocols (http://www.researchprotocols.org), 28.04.2017. This is an open-access article distributed under the terms of the Creative Commons Attribution License (http://creativecommons.org/licenses/by/2.0/), which permits unrestricted use, distribution, and reproduction in any medium, provided the original work, first published in JMIR Research Protocols, is properly cited. The complete bibliographic information, a link to the original publication on http://www.researchprotocols.org, as well as this copyright and license information must be included. 